\title{
BMJ Open Views on mandatory reporting of impaired health practitioners by their treating practitioners: a qualitative study from Australia
}

\author{
Marie M Bismark, ${ }^{1}$ Ben Mathews, ${ }^{2}$ Jennifer M Morris, ${ }^{1}$ Laura A Thomas, ${ }^{1}$ \\ David M Studdert ${ }^{3}$
}

To cite: Bismark MM, Mathews B, Morris JM, et al. Views on mandatory reporting of impaired health practitioners by their treating practitioners: a qualitative study from Australia. BMJ Open 2016;6:e011988. doi:10.1136/bmjopen-2016011988

- Prepublication history and additional material is available. To view please visit the journal (http://dx.doi.org/ 10.1136/bmjopen-2016011988).

Received 25 March 2016 Revised 1 July 2016 Accepted 7 September 2016

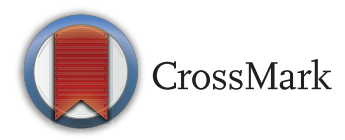

${ }^{1}$ Centre for Health Policy, Melbourne School of Population and Global Health, University of Melbourne. Melbourne, Victoria, Australia ${ }^{2}$ School of Law, Queensland University of Technology, Brisbane, Queensland, Australia

${ }^{3}$ Center for Health Policy/ Center for Primary Care and Outcomes Research Stanford Medical School \& Stanford Law School, Stanford University, Stanford, California, USA

Correspondence to Professor Marie Bismark; mbismark@unimelb.edu.au

\section{ABSTRACT}

Objective: To explore the views and experiences of health sector professionals in Australia regarding a new national law requiring treating practitioners to report impaired health practitioners whose impairments came to their attention in the course of providing treatment.

Method: We conducted a thematic analysis of indepth, semistructured interviews with 18 health practitioners and 4 medicolegal advisors from Australia's 6 states, each of whom had experience with applying the new mandatory reporting law in practice.

Results: Interviewees perceived the introduction of a mandatory reporting law as a response to failures of the profession to adequately protect the public from impaired practitioners. Mandatory reporting of impaired practitioners was reported to have several benefits: it provides treating practitioners with a 'lever' to influence behaviour, offers protections to those who make reports and underscores the duty to protect the public from harm. However, many viewed it as a blunt instrument that did not sufficiently take account of the realities of clinical practice. In deciding whether or not to make a report, interviewees reported exercising clinical discretion, and being influenced by three competing considerations: protection of the public, confidentiality of patient information and loyalty to their profession.

Conclusions: Competing ethical considerations limit the willingness of Australian health practitioners to report impaired practitioner-patients under a mandatory reporting law. Improved understanding and implementation of the law may bolster the public protection offered by mandatory reports, reduce the need to breach practitioner-patient confidentiality and help align the law with the loyalty that practitioners feel to support, rather than punish, their impaired colleagues.

\section{INTRODUCTION}

Since the time of Hippocrates, doctors have been bound by three core ethical duties: ${ }^{1}$ protection of patients ('I will keep (the sick)

\section{Strengths and limitations of this study}

- This is the first qualitative study of Australia's far-reaching new mandatory reporting laws, which extend to health practitioners who provide clinical care to an impaired practitioner.

- The open-ended nature of our qualitative design allowed unanticipated findings to emerge, such as the impact of confidence in regulatory processes on treating practitioners' decision-making.

- The sample included the views of treating practitioners and medicolegal advisors who had varied professional and geographic characteristics.

- We deliberately selected interviewees who had experience with applying the new mandatory reporting law in practice, which may limit the generalisability of our findings to 'average' practitioners.

from harm and injustice'); confidentiality ('What I may see or hear in the course of the treatment ... I will keep to myself') and loyalty to the profession ('To hold him who has taught me this art as equal to my parents'). Codes of practice for other health professions impose similar duties. ${ }^{2}{ }^{3}$ These duties may conflict sharply with each other in situations where a health practitioner, during the course of treating a colleague, becomes aware of an impairment that may affect the colleague's ability to practice safely.

Since 2010, health practitioners in Australia have had a legal obligation to notify the Australian Health Practitioner Regulation Agency (AHPRA) if they have a reasonable belief that another health practitioner has practiced while intoxicated, engaged in sexual misconduct, significantly departed from professional standards or placed the public at risk of substantial harm because of an impairment (table 1). The purpose of the legislation is to protect the public, by 
Table 1 Requirements for mandatory reporting of health practitioner impairment ${ }^{45}$

Who has a duty to report?

Who can be subject to a report?

What conduct must be reported?

How is impairment defined?

What is the reporting threshold?

Are there any exemptions?

What protection is offered to the reporter?

What are the consequences of failing to report?
All registered health practitioners (s141).

All registered health practitioners and students (s141).

A practitioner has placed the public at risk of substantial harm in the practitioner's practice of the profession because the practitioner has an impairment (s140). Impairment means a physical or mental impairment, disability, condition or disorder (including substance abuse or dependence) that detrimentally affects the person's capacity to practise the profession (s5).

A 'reasonable belief' that notifiable conduct has occurred ( $(141)$.

Where the threshold for a mandatory report has not been met, a treating practitioner may still choose to make a voluntary notification if they believe a practitioner-patient has, or may have, an impairment (s144(1)(d)).

All states and territories: Belief is formed in specific circumstances relating to the provision of legal advice, indemnity insurance or approved quality assurance activities (s141(4)).

Western Australia: Belief is formed in the course of providing health services to the health practitioner. ${ }^{5}$

Queensland: Belief is formed as a result of providing a health service to the health practitioner and the impairment will not place the public at substantial risk of harm; and is not professional misconduct. ${ }^{6}$

A report made in good faith is protected from liability and 'does not constitute a breach of professional etiquette or ethics' (s237).

Failure to report can be referred to the relevant Board for consideration as to whether the failure constitutes misconduct and sanctions may apply (s140). ensuring that practitioners practice in a competent and ethical manner. ${ }^{4}$ Controversially, the mandatory reporting duty extends to practitioners who provide clinical care to an impaired practitioner, such as a psychiatrist who treats an anaesthetist with a substance use disorder or a neurologist who cares for a general practitioner with dementia. Such 'treating practitioners' and 'practitioner-patients' form the focus of this study.

Australia is not the only jurisdiction to have mandated reporting of practitioner-patients. New Zealand ${ }^{7}$ and some US states ${ }^{8}$ have similar requirements. However, three features of the Australian provisions make them unusually far-reaching. First, they apply to treating practitioners in 14 health professions, ranging from Aboriginal and Torres Strait Islander health practice to psychology, not merely to medical practitioners. Second, the reporting requirement is triggered by identification of a past risk of substantial harm, rather than future risks. ${ }^{4}$ And third, unlike some US laws, there is no safe harbour from reporting in situations where the practitioner-patient agrees to participate in an approved treatment programme. ${ }^{9}$ It should be noted that some exemptions for mandatory reporting by practitionerpatients exist in the states of Queensland and Western Australia, but there is none in Australia's other four states and two territories.

Mandatory reporting, especially by treating practitioners, is controversial. Proponents assert that disclosure of an impairment that places the public at risk of substantial harm is necessary to protect patients. ${ }^{10}$ Opponents argue that this approach deters help-seeking and drives impaired practitioners underground. ${ }^{11}$ The Australian Medical Association has led the call for treating practitioners to be exempt from the duty to report impaired health practitioners. ${ }^{12}$ A recent independent review of the national law, commissioned by the Australian state and federal health ministers, expressed the same view. $^{13}$

Debate over the desirability of imposing mandatory reporting requirements on treating practitioners has occurred against a background of scant evidence about the attitudes and practices of practitioners who encounter such situations. In deferring action on the recommendation of the independent review, the Australian health ministers concluded that 'data is inconclusive' and that further research is needed to inform a national approach. ${ }^{13}$ To date, the only empirical study into mandatory reporting behaviour in Australia found that such reports are rare events. ${ }^{14}$ Over a 13-month period, only 816 mandatory reports were lodged with AHPRA (18 reports per 10000 practitioners per year), <10\% of which were made by treating practitioners. The rest were lodged by non-treating colleagues, employers or education providers. ${ }^{15}$ When coupled with available data regarding the prevalence of impairment among health practitioners, ${ }^{16}$ these findings indicate that, even in the presence of a legal duty, treating practitioners remain unlikely to report their practitioner-patients.

One shortcoming of previous research was that, as a purely quantitative analysis of reports made to AHPRA, it had almost no information on the settings from which the reports arose, and the motivations and attitudes of the treating practitioners who made them. To better understand the knowledge and attitudes of practitioners towards their mandatory reporting duties and their experiences in dealing with impaired practitioner- 
patients under the new regime, we collected qualitative data from treating practitioners and medicolegal advisors in each of Australia's six states.

\section{METHODS}

Approach

Owing to the limited existing evidence base, the wide range of unanswered questions about reporting behaviour, and the exploratory nature of our inquiry, a qualitative study design was chosen. Using purposive sampling, we recruited 18 health practitioners and 4 medicolegal advisors (table 2). Potential interviewees were identified through specialist colleges, professional associations, and the authors' professional networks, and approached by email with a request to participate. They were informed that the research was being undertaken to better understand knowledge, attitudes, and behaviours in relation to mandatory reporting in Australia. Nobody who was approached to participate declined to do so. Some interviewees were known to the research team through their various leadership roles in the healthcare sector.

Given the rarity of mandatory reports by treating practitioners, we focused on identifying health practitioners who had experience with applying the new mandatory reporting law in practice.

This included those with direct personal experience working with impaired health practitioners (eg, within a psychology practice or doctors' health service), or those

\begin{tabular}{|c|c|}
\hline Characteristics & $\begin{array}{l}\text { Interviewees } \\
(\mathrm{n}=22)\end{array}$ \\
\hline \multicolumn{2}{|l|}{ Sex } \\
\hline Female & 12 \\
\hline Male & 10 \\
\hline \multicolumn{2}{|l|}{ Profession } \\
\hline Medicine & 13 \\
\hline Psychiatrist & 4 \\
\hline General practitioner & 3 \\
\hline Physician & 2 \\
\hline Emergency physician & 2 \\
\hline Surgeon & 1 \\
\hline Junior doctor & 1 \\
\hline Nurse & 3 \\
\hline Psychologist & 2 \\
\hline Lawyer & 4 \\
\hline \multicolumn{2}{|l|}{ Other professional role } \\
\hline $\begin{array}{l}\text { Regulator (eg, member of Medical } \\
\text { Board or Nursing Board) }\end{array}$ & 5 \\
\hline $\begin{array}{l}\text { Professional body (eg, leadership of a } \\
\text { College or Association) }\end{array}$ & 3 \\
\hline $\begin{array}{l}\text { Practitioners' health service (eg, } \\
\text { Doctors' Health Advisory Service) }\end{array}$ & 2 \\
\hline Medicolegal advisor & 4 \\
\hline
\end{tabular}

in a professional leadership role (eg, senior members of professional colleges or associations) that connected them with the views and experiences of other practitioners. We included both practitioners who had actually made a mandatory report, and those who had weighed up whether or not to make a report and decided not to.

Our sampling strategy aimed to recruit individuals with a wide range of experiences and perspectives. The sample included general practitioners, internal medicine physicians, psychiatrists, emergency physicians, psychologists and nurses, This is because these groups have previously been identified as most likely to make a mandatory report. $^{15}$

To gain perspectives from those with broader and more regular involvement with mandatory reporting, we also included medicolegal advisors who regularly provide advice to treating practitioners regarding their responsibilities under the mandatory reporting law. In the course of their day-to-day work, these professionals provide advice and assistance to large numbers of practitioners regarding mandatory reporting. As such, they were able to describe and discuss the views and experiences of multiple practitioners who faced decisions about whether to make a mandatory report about a practitioner-patient.

Interviewees came from each of Australia's six states. The study was approved by the University of Melbourne Human Research Ethics Committee.

\section{Interviews and analysis}

Data was collected using semistructured interviews. Interviews were conducted using a pre-prepared interview guide. The interview guide was not formally piloted but was subject to minor modifications after the first two interviews, to improve the clarity of the questions. All interviews were conducted by one author (MMB), who is a public health physician and lawyer experienced in qualitative research. Prior to interview, interviewees were informed that MMB's involvement was funded through a research fellowship awarded by the Royal Australasian College of Physicians, and that the research was conducted independently of the funder.

All interviews were conducted face-to-face or via telephone between August 2014 and July 2015. Interviews were attended by only the interviewee and MMB, with face-to-face interviews conducted either at the interviewee's workplace, or the University of Melbourne. Interviews lasted between 25 and $45 \mathrm{~min}$ (mean $32 \mathrm{~min}$ ). Interviewees were asked to describe changes following the introduction of mandatory reporting, to discuss barriers and incentives to reporting, and to reflect on any ethical and legal tensions in this area. All interviews were audiotaped and professionally transcribed. The interviewer also made field notes during and after the interviews. Transcripts were not provided to interviewees for checking, nor were interviewees asked to provide feedback on the subsequent findings. We used a thematic analysis approach ${ }^{17}$ in order to 
identify a set of major themes among the views expressed. Two investigators with experience in qualitative research read transcripts from the first five interviews independently, and identified core themes that emerged. The use of N-Vivo software facilitated this step. The two investigators then compared their determinations and resolved any discrepancies by consensus. Finally, one investigator (MMB) applied the draft coding framework in reviewing and coding all interview transcripts, modifying the framework as necessary through an inductive and iterative process. Regular discussions among the research team members assisted development of the final framework. A copy of the coding tree can be provided by the researchers on request. Interviewee recruitment and interviews continued until there was consensus among the authors that no significant new themes were emerging (ie, data saturation was reached).

\section{RESULTS}

\section{General knowledge and attitudes}

All interviewees were aware of the introduction of the mandatory reporting regime. However few interviewees, other than the four medicolegal advisors, were familiar with the exact wording of the legislation. As one practitioner explained:

Look, I think it's understood fairly poorly. I think at least among the colleagues that I work with; we understand that there's some obligation to report if [a] health practitioner is impaired and there's some ramifications or some consequence if we don't report, but apart from particularly egregious cases... I don't think we have a great understanding on when to report. (P13)

The law was widely seen as an attempt to codify longstanding ethical responsibilities and as a response to perceived failures by the health profession to live up to those ethical and professional obligations.

Public expectation has clearly been influenced by examples where medical practice failed to report matters that should have been reported, no question. And that public quite rightly say: doctors have covered up for doctors, in essence. They have every right to, and they have some very good exemplars to point to. (P3)

Any time you talk to professions people would say yes, we know we need to act if somebody's placing the public at risk, but the amount of song and dance there was about introducing mandatory schemes suggests that actually there was a gap between what people were actually doing despite what they said. (P8)

The majority of interviewees supported the general intent of the law, describing it as 'a wake-up call that [the profession] can't turn a blind eye' (P11) to practitioner-patients who place patients at risk. One general practitioner hoped the law would help overcome the temptation for practitioners to avert their gaze from practitioner impairment and 'hope nothing goes wrong' (P15).

However, this support was tempered by concern that the law, as it is currently worded, is a 'blunt instrument' (P19) which fails to acknowledge the nuanced clinical judgement involved in deciding whether or not an impaired practitioner-patient ought to be reported.

I worry about legislation which purports to be about black and white when we know that the real world is incredibly grey. (P5)

\section{Conflicting duties}

When discussing the advantages, disadvantages, and implementation of the new law, interviewees consistently referred to three key considerations: protecting the public from harm, respecting confidentiality, and showing loyalty to the profession.

\section{Protection}

All interviewees mentioned an obligation to prevent harm in circumstances where a practitioner-patient is unable to practice safely. A fairly typical characterisation of this duty was as follows:

If doctors are aware of another doctor that's practising not with patient care first and foremost in their mind, we have a duty of care to protect the public, and I really believe that. (P7)

Other interviewees emphasised that mandatory reporting of impaired practitioners was consistent with their broader ethical duty to protect third parties from a threat of harm. Five interviewees drew specific parallels with the health practitioners' obligations to report child abuse or certain types of infectious diseases.

Interviewees described two conceptually distinct ways in which the reporting regime's protective function operated. One scenario involved using the threat of a report as a means of persuading impaired practitionerpatients to appropriately cease or limit their own practice while they took appropriate steps to address their impairment.

[It is] a very powerful negotiating tool to say listen ... if you don't stop working I will have to report you, I don't get a choice in the matter. But if you stop working, if you do whatever needs to be done to manage this risk then actually I no longer have a mandatory reporting obligation. So [that] protected the public and meant the doctor got the help that they needed. (P9)

Several interviewees reported having successfully used the threat of a report to persuade a non-compliant practitioner 'to behave in a sensible, responsible fashion' (P16) in relation to their own health needs.

I think for [the treating practitioner] to be able to say if you don't take your antidepressants I will need to report 
you to the Medical Board-I don't have any choice in this matter, here's the law. Now go and pull your finger out. That's actually very powerful. (P8)

An alternative approach, reserved by most interviewees for circumstances in which the threat of a report was insufficient to provoke remediation or protect the public, was the actual making of a report to the Board, which could then forcibly restrict the practice of an impaired practitioner.

[If] a mandatory report resulted in a person who should not be practising at that point in time not practising, I would say that's been a good thing. (P1)

Practitioners who had made such reports noted that, in addition to protecting patients, regulatory action could occasionally be of 'great benefit' (P3) to the practitioners themselves, who would otherwise 'just keep going, keep going' (P19) with self-destructive behaviour.

We've had a couple of doctors that we've tried really hard to work with, and it's not until we've had to mandatory report them, and they really felt the heat of the Medical Board, that it actually dawned on them, they had tosomething had to change ... I can bring to mind a couple of people, at least, where mandatory reporting has saved their careers. (P19)

However, the efficacy of actual reporting in ensuring public protection obviously hinges on the responsiveness of the regulator and the efficacy of the regulator's response. Several interviewees emphasised the importance to them, as reporters, of what happened after their reports reached AHPRA and the practitioner boards. If the regulator was perceived to be unresponsive, or as responding inappropriately, this would influence how the reporter weighted trade-offs between a desire for public protection and competing considerations, such as confidentiality and a desire to support colleagues.

\section{Confidentiality}

A second competing ethical principle discussed by interviewees was their deep commitment to maintaining the confidentiality of information shared by patients within therapeutic relationships. Confidentiality was described as a critical prerequisite for practitioner-patients to speak openly and honestly about their health concerns. A number of interviewees described apprehension about confidentiality among impaired practitioners who sought treatment and various strategies these practitioners used to protect themselves. For example, one interviewee noted:

I've had senior surgeons...contact me with "hypothetical" situations [but] they don't want to go through the normal channels, 'cause they're fearful they'll be kept from the operating theatre.... (P16)

Several interviewees commented on additional measures they offered to practitioner-patients-over and above the usual assurance of patient confidentiality-to secure their trust and co-operation. One example was the use of a pseudonym in their medical records.

There was a strong preference for managing practitioner-patient impairment within the confines of a confidential therapeutic relationship wherever possible.

I think there has to be some discretion in that so that people who are turning themselves in for help at an early stage aren't fearful that 'I'm going to be struck by the letter of the law', that 'this will be applied rigidly against me'. (P14)

Several interviewees remarked that, when treating practitioners reached a point where they felt a report to a regulator was necessary, it was good practice to discuss the need for the report with the patient first and encourage them to self-report.

Two practitioners noted with sadness that breaking patient confidentiality to make a report about a practitioner-patient had brought an end to the therapeutic relationship.

When you make a report you lose a patient. There is so much about that doctor-patient confidentiality and trust and respect and for them to be open and honest enough to tell you that ... and then you have to report them. (P7)

Beyond the personal angst associated with breaking confidence, treating practitioners also expressed concern about the wider implications of undermining trust in patient confidentiality. In particular, there was concern that reports may dissuade other impaired practitioners from seeking care:

Someone who has come to attention [isn't the real] issue, it's someone who is practically outside the system and reluctant to seek help. (P11)

Many interviewees noted that help-seeking by health practitioners 'was a problem well and truly prior' (P16) to the current mandatory reporting requirements and that doctors, in particular, had a long history of "treating their patients very well and themselves very poorly' (P20). Interviewees feared that inflexible reporting requirements that are focused on past rather than future risk could exacerbate existing barriers to helpseeking by imposing 'a deterrent effect on people seeking help and that's not helpful for themselves or for their patients' (P9).

It's a real problem if it puts in place another barrier to health professionals seeking help, because they know that by revealing their problem to a health professional, who's bound to report them, it just drives it further underground. (P15) 


\section{Loyalty}

Tension between the two imperatives of public protection and patient confidentiality are familiar in medical practice. A variety of other forms of external reportingranging from child abuse and domestic violence to driver impairment and certain infectious diseases-constitute widely-accepted incursions into the privacy of the therapeutic relationship. ${ }^{18}$ However, mandatory reporting of practitioner-patients introduces an additional tension: loyalty to other health practitioners and to one's profession more broadly.

Interviewees described feeling a 'far greater sense of discomfort' (P16) reporting impaired fellow practitioners than they did conforming to other forms of external reporting. Interviewees attributed this heightened sense of unease to concerns about professional loyalty, and a 'tribal sense' (P5) that made it 'difficult to dob in their peers' (P14).

One of the reasons for the initial reactions to mandatory reporting is that it crossed a traditional set of values, I think, that were imbued in medicine about looking after each other, and ... a strong reluctance to report impairment among peers. (P1)

Sometimes this sense of loyalty was motivated by genuine empathy and concern for a fellow health practitioner. Interviewees reported that the obligation to report created 'a really horrible situation' (P7) even when it was 'the right thing to do' $(\mathrm{P} 7)$.

I think practising psychiatrists still weigh strongly the discomfort about reporting another medical practitioner, a sense of collegiality, a sense of perhaps there but for the grace of God go I. Yeah, so an empathy. (P1)

There's that dilemma of wanting to do the right things by your colleagues in the same way that you'd want them to support you. (P16)

But for some interviewees, loyalty was laced with professional self-interest. They were acutely aware that the 'club culture' of medicine expected loyalty to the profession and feared that reporting concerns about the health of a 'revered' practitioner could have 'blowback' (P1) for their own career.

There would be a concern about [your] reputation being tarnished, that [you] weren't a person to be trusted, that [you] would have broken some kind of collegial code which is expected amongst practitioners, that you stick together. (P14)

\section{Shifting balance}

Australia's new mandatory reporting regime did not create the three competing ethical considerations described above. It merely raised the stakes and brought them into sharper focus. Interviewees were divided about the impact the regime actually had on how practitioners navigated these tensions. Approximately half of them believed that the introduction of the law had supported a cultural shift away from professional loyalty towards a stronger focus on protecting the public:

I think the upside is in those situations where it's very clear that patient safety is at risk. It is now very clear that it is a professional responsibility to report those behaviours and I think that's slowly but hopefully progressively driving the professional culture change we need. (P5)

Several members of this group remarked that protections the legislation provides for whistle-blowers helps take some of 'the agony' (P8) out of the decision to report. Three interviewees went further, describing the mandate as a 'shield' against perceptions of professional disloyalty:

I think there's something very psychologically and socially strengthening in being able to say, I wouldn't want to do this; I wouldn't go ahead and do this, but the law requires me to, and I'm sorry but that's what I've got to do. Sometimes the law can act as a shield in more ways than you first imagined. (P14)

In contrast, seven interviewees took the view that the impact of the law on the ground had been "considerably less change than was anticipated at the time of the introduction of the new requirements." (P1) Within this group were three treating practitioners with long histories of working with impaired practitioners, who felt the new law had not appreciably changed their threshold for reporting.

Whether you've got mandatory reporting or not, as a medical practitioner, you've still got an ethical obligation. And the number of people that I have reported to the Medical Board, since I've been working here, is very small. But all the people I have reported since mandatory reporting came in-I would have reported those people anyway. (P19)

For me, personally, I would make a report if I felt it was necessary, regardless of the law mandating whether I have to or not. (P13)

\section{Complex clinical judgement}

Regardless of their views on the impact of the new law, interviewees generally agreed that reporting an impaired practitioner-patient required a complex balancing act: 'making a judgement about this person on that day in their context' (P15). One interviewee commented that reporting requirements needed to be interpreted 'sensibly', rather than rigidly applied (P16).

If in doubt, report; that's what a mandatory reporting requirement is. But I don't believe it's quite that simple. (P1)

However, rather than referring to the specific words of the legislation, with which few interviewees except the medicolegal advisors were familiar, interviewees 
repeatedly discussed the centrality of 'clinical judgement' to decisions about whether to make a report.

You can have all the laws you like, it's down to the people and whether they're going to use them. (P17)

In making this assessment, practitioners spoke about taking into account a complex range of factors that are not mentioned in the legislation. Three factors were mentioned by multiple interviewees: self-corrective steps taken by the practitioner-patient, the risk of future harm and the probable consequences of a report.

\section{Self-correction}

Treating practitioners expressed a deep uneasiness about reporting practitioners who had sought help for a health condition if those patients recognised the risk that their impairment presented and were willing and able to take steps to mitigate that risk:

If they have insight into their problem, if they recognise that patients are at risk, they're willing to take a long holiday, they're willing to seek counselling, if they're willing to do what they need to do then, to my mind... that doesn't need reporting. (P5)

In my mind if they're actually asking for help and if they're coming for help and they're adhering to it and compliant then I don't think that justifies a mandatory report. (P7)

\section{Potential for future harm}

The mandatory reporting law in Australia requires treating practitioners to make a report in situations where a practitioner has at some point up to that moment 'placed the public at risk of substantial harm'. Yet, in weighing up their competing ethical responsibilities, practitioners were not focused on the practitionerpatient's history. Rather, they were much more interested in the risk of future harm, taking into account the practitioner's prognosis, history, practice environment and treatment plan.

\section{The probable consequences}

Interviewees were strongly influenced by the likely consequences of a report. Many interviewees commented that they would be more willing to make a report if they had confidence that the regulatory response would be timely, fair and supportive. In practice, interviewees felt quite unsure about how the practitioner-patient would be treated if report was made. Several of those who had made a report worried that the regulatory response may have harmed the practitioner-patient by imposing additional stress and anxiety about their future at a time when they were already unwell:

[The Medical Board's] role is not to punish. But sometimes people do feel punished by the process because it is a-it becomes quite a legalistic process...it's hard going. (P9)

\section{Box 1 Clinical decision-making process}

\section{Decision not to report}

I would interpret the guidelines sensibly in my book... I have been in the situation, for example, of a senior member of a [medical] unit ... who I knew as a patient. She had her HIV under good control, on therapy, undetectable virus. So I considered first of all, she was unlikely to be involved in an exposure, and second of all, unlikely to transmit anything should an exposure occur, and the final icing on the cake was she gave me a written assurance that if she were ever involved with a needle stick injury, she would immediately disclose her [HIV] status to her manager. So there was every level of safety in place, and had no problem with that.... Part of my reluctance to report is I'm not convinced [the regulator] would necessarily act on a report promptly, and...if they did...perhaps they'd act unfairly. (P16)

\section{Decision to report}

The guy who drinks a bottle and a half every night-tries to guarantee that his blood alcohol is zero every morning, but you know that he's got this huge problem that has affected every other aspect of his life, and his world's falling apart, and finally it's going to show up at work one day. You're constantly on the lookout for-have we got this under control? Have we got him completely sober, or is he managing with the controlled drinking? Is he dry, has he had a relapse? Anything happened at work? We're doing our best to help [him] get on top of it...we want to make sure he's not going to jeopardise his career. It's a bit like we're the carrot, and the Board's the stick.... And it's really hard when somebody's-a report has gone in for somebody-and they're left for months, in limbo-land, wondering whether they've got a career or not.... Finally his alcoholism has declared itself at work, and he's been found slumped over his desk, and he can't do his job. That guy would get reported.... That's doing something that we would have done on a clinical basis, an ethical basis anyway, because we would have felt that that person was at risk of harming their patients, and things. (P19)

After weighing all these factors, practitioners made an assessment of the relative harms and benefits of making a report. Box 1 provides illustrative examples from two interviewees on how they reached a decision to report, or not report, a practitioner-patient with a health impairment.

\section{DISCUSSION}

Australia's mandatory law has been the subject of vigorous debate, but the debate has occurred in a vacuum of evidence about the law's impact or effectiveness and the attitudes and experiences of practitioners in applying it. This qualitative study explored the views and experiences of 18 health practitioners and 4 medicolegal advisors on mandatory reporting by treating practitioners of impaired practitioner-patients.

\section{Purpose of mandatory reporting}

A major finding of this study relates to interviewees' knowledge of and attitude towards the general purpose 
of the law. There was widespread acceptance among interviewees that certain types of public health concerns can trump the general duty of patient confidentiality, as they do with respect to other conditions, such as child abuse and infectious disease, which are subject to mandatory reporting. Furthermore, all interviewees agreed that minimising the risk posed to patients by practitioner impairment-the public health policy goal which underpins the mandatory reporting law-is an important aim. Where interviewees diverged was with respect to the question of whether mandatory reporting laws are an effective mechanism by which to achieve this goal.

Approximately one-third of interviewees opposed mandatory reporting obligations for treating practitioners under any circumstances, opining that decisions about reporting should always be left to individual practitioners. However, a majority supported mandatory reporting requirements for treating practitioners in certain circumstances. Among such guarded supporters were a number of interviewees who had experienced tensions and reticence when faced with the decision of making such a report. In their view, the existence of the legal duty provided practitioners with a 'lever' to influence the behaviour of impaired practitioners, offered protections to those who did make reports and underscored the duty to protect the public from harm.

There are some internal tensions in these findings. On the one hand, some of the practitioners we interviewed opposed any kind of mandatory reporting law. On the other hand, everyone supported the overriding policy goal of minimising the risk posed to patients by practitioner impairment. How can these standpoints be reconciled? One interpretation is that practitioners have misconceived the nature of the reporting duty and its parallels with existing ethical duties to protect third parties from harm. Perhaps the kind of case they envisage as triggering the requirement to report is not, in fact, the target of the law. Indeed, the Medical Board has seen the need to issue a number of statements clarifying that the threshold for reporting is high and is not triggered in situations where a practitioner is compliant with treatment and any risk to the public has been appropriately managed. ${ }^{19}$ An alternative interpretation is that practitioners have adopted a utilitarian approach and believe that the good achieved by reporting practitioners with impairments-at least under the current regulatory system-is outweighed by the harm associated with discouraging other impaired practitioners from seeking help for their impairing conditions.

\section{Interface with clinical practice}

Another major finding is that, regardless of whether they supported the existence of a mandatory duty to report, all interviewees identified deficiencies in the way that the legal regime currently operates. These concerns focused on three areas: knowledge, content and administration of the law.

\section{Knowledge of the law}

The first concern was that, while the medicolegal advisors had a predictably strong knowledge of the law, most interviewees felt that health practitioners did not have a clear understanding of their obligations. (Indeed, it was apparent that the interviewees themselves, who were sampled specifically because of their familiarity with the reporting regime, exhibited a shaky grasp of some of its details.) Studies of other mandatory reporting regimes have also found that mandated reporters often do not have the required training to properly fulfil their role. ${ }^{20}$ A fundamental tenet of the rule of law is that a law must be reasonably intelligible, clear and predictable for those to whom it applies. ${ }^{21}$ Yet interviewees relied heavily on medical indemnity providers for advice on their reporting responsibilities.

Interviewees also noted that it was difficult to access any case studies on mandatory reporting by treating practitioners or to obtain real-time advice on their obligations from AHPRA. This reported absence of sufficient education is a flaw in implementation. However, it is a remediable flaw. ${ }^{22}$ All practitioners need and deserve sufficient education about the nature of the mandatory reporting law, its context, purpose, scope and method of implementation. This will better enable effective reporting behaviour, limit ineffective reporting behaviour and foster attitudes conducive to relevant policy goals. ${ }^{20} 23$ One component of this training should be case studies demonstrating the range of potential scenarios and appropriate responses. In particular, concrete information on what constitutes a 'substantial harm' is essential. At present, far too much is left to the eye of the beholder. Such education would provide treating practitioners and practitioner-patients with the understanding necessary to ensure smooth operation of the reporting rules. Besides enabling reporters to fulfil their duties, it may help dispel misperceptions that discourage help-seeking among impaired practitioners.

\section{Content of the law}

The second concern was that the wording of the law failed to accord with the realities of clinical decisionmaking. Interviewees emphasised a range of clinical and contextual factors-not mentioned in the legislationthat need to be taken into account in resolving the three-way tension between patient confidentiality, protection of the public and loyalty to colleagues. This finding resonates with previous research on mandatory reporting of child abuse, which showed that a range of case characteristics influence reporting intentions. ${ }^{24}$

As it stands, some elements of discretion are already built in to the reporting duty. For example, the concept of 'reasonable belief' requires the practitioner to discern grounds for believing that the practitioner has an impairment and that, because of the impairment, the practitioner has placed the public at risk of substantial harm. If these conditions are not present, the duty is not activated and the practitioner is entitled to take 
other lesser steps to encourage the practitioner to seek assistance voluntarily. Seen in this way, the legal duty does already offer some leeway for choices to be informed by the clinical context and circumstance. However, practitioners remained concerned that the focus on past behaviour fails to take into account whether or not a practitioner-patient was willing and able to comply with an appropriate treatment plan. This finding is consistent with a recent review of mandatory reports by treating practitioners which found that most mandatory reports involve a practitioner-patient who lacks insight, is dishonest with the treating practitioner or shows a reckless disregard for patient safety. ${ }^{15}$

\section{Administration of the law}

Finally, some interviewees expressed a lack of confidence in the ability of the regulator to respond to mandatory reports in a fair, timely, predictable and effective manner. This finding is consistent with results of previous studies that have found that failure to make a mandatory report is often associated with a belief that reporting will not result in an effective response. ${ }^{25} 26$ The concern is further heightened in the context of reporting an impaired peer. Involvement in medicolegal processes can be highly stressful, for whistle-blowing practitioners and for health practitioners who are subject to complaint. ${ }^{27} 28$

When regulatory outcomes are seen as unpredictable, or likely to exacerbate rather than address the impairment, incentives not to report, spurred by considerations of patient confidentiality and professional loyalty, are more likely to hold sway.

Research in other contexts has shown that mandated reporters respond well to their duties, and sustain their intrinsic confidence and commitment to fulfilling them, when supported by robust and responsive systems. ${ }^{23} \mathrm{~A}$ sound regulatory system needs to possess sufficient oversight and responsive capacity ${ }^{29}$ and the system must not only require compliance by the regulated actors, but must demonstrate accountability to those actors. In this context, this could include (1) ensuring prompt responses to reports, (2) provision of information to the reporter about the resulting processes and outcomes and (3) appropriate and proportional responses to the concern, occurring along a spectrum from providing support and rehabilitation to disciplinary measures.

\section{Strengths and limitations}

The requirement for treating practitioners to report impaired practitioner-patients is currently under review in Australia. By examining practitioners' and medicolegal advisors' perspectives on mandatory reporting, this study provides important information for these deliberations.

Some of the findings in this study relate to specific aspects of the Australian legal and regulatory context. However, many of the broader themes, such as the threepronged framework for conceptualising ethical tensions and the importance of practitioner trust (or lack thereof) in regulatory systems, provide important points of consideration for those in other jurisdictions. This includes jurisdictions where mandatory reporting already exists, as well as those where its introduction is being considered.

The study has several strengths. The open-ended nature of our qualitative design allowed unanticipated findings to emerge, such as the impact of confidence in regulatory processes on treating practitioners' decision-making. The sample included the views of treating practitioners and medicolegal advisors who had varied professional and geographic characteristics.

However, the study had weaknesses too. Our sample size was small and interviewees were not representative of clinicians affected by the law; on the contrary, they were selected based on their experience with mandatory reporting. While this approach avoided inclusion of interviewees who were unaware of or apathetic about the law, it raises questions about generalisability of our findings to 'average' practitioners. In addition, the study was designed as an exploratory study and as such was not large enough to support stratified analyses of differences in views between different professions.

\section{CONCLUSIONS}

On the basis of the findings from this study, we offer three recommendations for improving the operation of Australia's mandatory reporting regime, as it is applies to the obligations of treating practitioners with respect to practitioner-patients. These recommendations aim to reduce the tensions-real or perceived-between competing considerations of public protection, confidentiality and loyalty.

First, greater efforts should be made to educate practitioners about the scope of their duty under the law. At a minimum, these efforts must provide practitioners with guidance regarding how they approach the more subjective elements of the law, including the concepts of 'reasonable belief' and 'substantial harm'. In a recent case involving an impaired pharmacist, a Tribunal in New South Wales expressed concern that the failure to make a notification was "indicative of a failure to understand, or properly implement, the mandatory notification provisions in the National Law." ${ }^{30}$

If many practitioners do not know the precise scope and function of the law, or worse, have a misinformed and an exaggerated sense of their reporting obligations, they are almost certainly more likely to view the law as a blunt instrument that is insensitive to the realities of clinical practice.

Second, even supporters of the law should accept that it has a flaw that is out of step with similar regimes in other places and should be rectified. Under the current law, any practitioner who has placed the public at risk of substantial harm in the practitioner's practice of the profession because of an impairment must be notified, even 
if their condition is now being effectively managed. The reporting duty should be amended to explicitly assure access to confidential treatment (ie, no need to report) for practitioners who voluntarily participate in an agreed treatment plan and take necessary steps to protect patients from harm (eg, by limiting the nature or extent of their practice for a period of time). This would largely restrict notifications to situations where a practitioner is unable or unwilling to comply with an appropriate management plan and may therefore encourage help-seeking behaviour among practitioners with health concerns.

Finally, regulators, practitioner health programmes, educators, insurers and professional bodies should work together to ensure that mandatory reports result in a fair, sensitive and timely response. Concerns that the regulatory response to mandatory reports is slow, stressful and unpredictable currently limit the willingness of Australian health practitioners to report impaired practitioner-patients. Little is known about the experiences of practitioners who have been subject to a mandatory report or the extent to which different regulatory responses may either exacerbate or help address health impairments. Greater transparency around likely outcomes of a report-as provided for example by the Legal Services Board in Victoria ${ }^{31}$ - combined with a more supportive and streamlined regulatory process would benefit practitioners, reporters and members of the public who may otherwise be exposed to a risk of harm.

In combination, these three measures may bolster the public protection offered by mandatory reports, reduce the need to breach practitioner-patient confidentiality and help align the law with the loyalty that practitioners feel to support, rather than punish, their impaired colleagues.

\section{Twitter Follow Marie Bismark @mbismark}

Contributors MMB and DMS developed the study idea and collected the data MMB, DMS, LAT and BM conducted the analyses; MMB wrote the first draft of the manuscript; BM, JMM, LAT and DMS helped revise the draft manuscript; all authors reviewed and agreed on the submitted version of the manuscript. MMB and DMS are guarantors for the study.

Funding This study was funded by a Fellows Career Development Fellowship awarded to MMB from the Royal Australasian College of Physicians. The research was conducted independently from the funder. The funder had no role in the study design, collection, analysis and interpretation of data; writing of the report or the decision to submit the article for publication.

Competing interests All authors have completed the Unified Competing Interest form and declare that (1) MMB has had support from the Royal Australasian College of Physicians; (2) none of the authors have had a financial relationships with any organisation that may have an interest in the submitted work in the previous 3 years; (3) none of the authors' spouses, partners or children have any financial relationships that may be relevant to the submitted work and (4) none of the authors have any non-financial interests that may be relevant to the submitted.

Ethics approval The study was approved by the Human Research Ethics Committee at the University of Melbourne.

Provenance and peer review Not commissioned; externally peer reviewed.
Data sharing statement No additional data are available.

Open Access This is an Open Access article distributed in accordance with the Creative Commons Attribution Non Commercial (CC BY-NC 4.0) license, which permits others to distribute, remix, adapt, build upon this work noncommercially, and license their derivative works on different terms, provided the original work is properly cited and the use is non-commercial. See: http:// creativecommons.org/licenses/by-nc/4.0/

\section{REFERENCES}

1. Markel H. "I swear by Apollo"-on taking the Hippocratic oath. N Engl J Med 2004;350:2026-9.

2. International Council of Nurses. The ICN code of ethics for nurses. Revised 2012 ed. Geneva: International Council of Nurses, 2012.

3. FDI World Dental Federation. International principle of ethics for the dental profession. Seoul: FDI World Dental Federation, 1997.

4. Health Practitioner Regulation National Law (Victoria) Act. Victoria (2009).

5. Health Practitioner Regulation National Law (WA) Act. Australia (2010).

6. Health Ombudsman Act. QLD, Australia (2013)

7. Health Practitioners Competence Assurance Act. New Zealand (2003).

8. Council of Ethical and Judicial Affairs. Reporting impaired, incompetent, or unethical colleagues. Chicago (IL): Council on Ethical and Judicial Affairs, American Medical Association, 1991.

9. Physician Health Service. Mandated reporting-exceptions. http:// www.massmed.org/Physician_Health_Services/Helping_Yourself_ and_Others/Mandated_Reporting_-_Exceptions/\#.Vp2XkFLQODk (accessed Mar 2016)

10. Parker M. Embracing the new professionalism: self-regulation, mandatory reporting and their discontents. J Law Med 2011;18:456-66.

11. Goiran HN, Kay M, Nash L, et al. Mandatory reporting of health professionals: the case for a Western Australian style exemption for all Australian practitioners. J Law Med 2014;22:209-20.

12. Australian Medical Association. Mandatory reporting laws backfire. 30 September 2014. https://ama.com.au/ausmed/ mandatory-reporting-laws-backfire (accessed Mar 2016).

13. Council of Australian Governments. Communique-final report on the independent review of the National Registration and Accreditation Scheme for health professionals. http://www. coaghealthcouncil.gov.au/DesktopModules/EasyDNNNews/ DocumentDownload. ash $x$ ?portalid=0\&moduleid=514\&articleid= 68\&documentid=74 (accessed Mar 2016)

14. Bismark MM, Spittal MJ, Plueckhahn TM, et al. Mandatory reports of concerns about the health, performance, and conduct of health practitioners. Med J Aust 2014;201:399-403.

15. Bismark MM, Spittal MJ, Morris JM, et al. Reporting of health practitioners by their treating practitioner under Australia's national mandatory reporting law. Med J Aust 2016;204:24.

16. Leape LL, Fromson JA. Problem doctors: is there a system-level solution? Ann Intern Med 2006;144:107-15.

17. Braun V, Clarke V, Terry G. Thematic analysis. In: Rohleder P Lyons A, eds. Qualitative research in clinical and health psychology. Basingstoke: Palgrave MacMillan, 2014:95-113

18. Brashler $\mathrm{R}$, Finestone $\mathrm{HM}$, Nevison $\mathrm{C}$, et al. Time to make a call? The ethics of mandatory reporting. PM R 2016;8:69-74. http://dx.doi. org/10.1016/j.pmrj.2015.11.009.

19. Australian Health Practitioner Regulation Agency. National Board guidelines for registered health practitioners: guidelines for mandatory notification. http://www.medicalboard.gov.au/ Codes-Guidelines-Policies/Guidelines-for-mandatory-notifications. aspx (accessed Mar 2016).

20. Christian CW. Professional education in child abuse and neglect Pediatrics 2008;122(Suppl 1):S13-17.

21. Bingham T. The rule of law. Cam LJ 2007;66:67-85.

22. Mathews B. Teacher education to meet the challenges of child sexual abuse. Aust J Teach Ed 2011;36:13-32.

23. Mathews B, Kenny MC. Mandatory reporting legislation in the United States, Canada, and Australia: a cross-jurisdictional review of key features, differences, and issues. Child Maltreat 2008;13:50-63.

24. Zellman GL. The impact of case characteristics on child abuse reporting decisions. Child Abuse Negl 1992;16:57-74.

25. DesRoches CM, Rao SR, Fromson JA, et al. Physicians' perceptions, preparedness for reporting, and experiences related to impaired and incompetent colleagues. JAMA 2010;304:187-93.

26. Jones R, Flaherty EG, Binns HJ, et al. Clinicians' description of factors influencing their reporting of suspected child abuse: report of 
the Child Abuse Reporting Experience Study Research Group. Pediatrics 2008:122:259-66.

27. Cunningham $W$. The immediate and long-term impact on New Zealand doctors who receive patient complaints. N Z Med J 2004;117:U972.

28. Jackson D, Peters K, Andrew S, et al. Understanding whistleblowing: qualitative insights from nurse whistleblowers. $J \mathrm{Adv}$ Nurs 2010;66:2194-201.
29. Sparrow MK. The regulatory craft: controlling risks, solving problems, and managing compliance. Washington (DC): Brookings Institution Press, 2011.

30. Health Care Complaints Commission v Orr [2015] NSWCATOD 124

31. Victorian Legal Services Board. Mental health policy. http://lsbc.vic. gov.au/documents/RRP_007_Mental_Health_Policy_V1_(Dec_11). pdf (accessed Mar 2016) 